\title{
Formative research to scale up a handwashing with soap and water treatment intervention for household members of diarrhea patients in health facilities in Dhaka, Bangladesh (CHoBI7 program)
}

Elizabeth D. Thomas ${ }^{1}$, Fatema Zohura², M. Tasdik Hasan², Md. Sohel Rana ${ }^{3}$, Alana Teman ${ }^{1}$, Tahmina Parvin², Jahed Masud ${ }^{2}$, Md. Sazzadul Islam Bhuyian², Md. Khobair Hossain², Maynul Hasan², Sanya Tahmina4, Farzana Munmun ${ }^{5}$, Md. Abul Hashem Khan", Shirajum Monira², David A. Sack ${ }^{1}$, Elli Leontsini ${ }^{1}$, Peter J. Winch', Munirul Alam² and Christine Marie George ${ }^{6^{*}}$ (i)

\begin{abstract}
Background: During the time a diarrhea patient presents at a health facility, the household members of the patient are at higher risk of developing diarrheal diseases (> 100 times for cholera) than the general population. The Cholera-Hospital-based-Intervention-for-7-Days (CHoBl7) is a health facility-initiated water treatment and handwashing with soap intervention designed to reduce transmission of diarrheal diseases between patients and their household members. The present research aimed to (1) develop a scalable approach to integrate the CHoBl7 intervention program into services provided at government and private health facilities in Bangladesh; and (2) tailor the intervention program for the household members of all diarrhea patients, irrespective of the etiology of disease.

Methods: We conducted 8 months of formative research, including 60 semi-structured interviews, 2 group discussions, and a pilot study. Thirty-two interviews were conducted with diarrhea patients and their family caregivers, government stakeholders, and health care providers both to explore existing WASH and diarrhea patient care practices in health facilities and to identify considerations for scaling the $\mathrm{CHoBI7}$ program. Fifty-two diarrhea patient households participated in a pilot study of a modified version of the $\mathrm{CHOBI}$ intervention program for tailoring. Twenty-eight interviews and 2 group discussions were conducted with pilot households to explore experiences with and recommendations for intervention delivery.

(Continued on next page)
\end{abstract}

\footnotetext{
* Correspondence: cmgeorge1@jhu.edu

${ }^{6}$ Associate Professor, Department of International Health, Program in Global Disease Epidemiology and Control, Johns Hopkins Bloomberg School of Public Health, 615 N. Wolfe Street, Room E5535, Baltimore, MD 21205-2103, USA

Full list of author information is available at the end of the article
}

(c) The Author(s). 2020 Open Access This article is licensed under a Creative Commons Attribution 4.0 International License, which permits use, sharing, adaptation, distribution and reproduction in any medium or format, as long as you give appropriate credit to the original author(s) and the source, provide a link to the Creative Commons licence, and indicate if changes were made. The images or other third party material in this article are included in the article's Creative Commons licence, unless indicated otherwise in a credit line to the material. If material is not included in the article's Creative Commons licence and your intended use is not permitted by statutory regulation or exceeds the permitted use, you will need to obtain permission directly from the copyright holder. To view a copy of this licence, visit http://creativecommons.org/licenses/by/4.0/. The Creative Commons Public Domain Dedication waiver (http://creativecommons.org/publicdomain/zero/1.0/) applies to the data made available in this article, unless otherwise stated in a credit line to the data. 


\begin{abstract}
(Continued from previous page)
Results: The intervention program was modified based on formative research findings. Pilot study participants recognized the benefits of the $\mathrm{CHoBI} 7$ intervention program and made suggestions to improve the acceptability and feasibility of the intervention. Modifications included 1) providing additional pictorial modules, cues to action, enabling technologies, and supplies for safe drinking water and handwashing with soap behaviors in the health facility; 2) switching out technology prone to breaks and leaks as well as sourcing plastic technologies from a highquality, local manufacturer; and 3) including instructions discouraging the non-use or misuse of technologies and supplies. Considerations for scalability include the local availability and marketing of enabling technologies and supplies, staff for program delivery in health facilities, and potential integration into existing government or health promotion programs.
\end{abstract}

Conclusions: Formative research identified important considerations for the content, delivery, and scalability of the CHoBI7 health facility-initiated WASH intervention program.

Keywords: Diarrhea, Handwashing, Water treatment, Behavior change, Health facilities, Qualitative research, Formative research, Bangladesh

\section{Background}

Diarrheal disease remains a leading cause of child death and a major contributor to morbidity across all age groups $[1,2]$. During the time a diarrhea patient presents at a health facility for treatment, the household members of the patient are at much higher risk of developing diarrheal diseases ( $>100$ times for cholera) than the general population [3-7]. This higher risk is likely due to shared, contaminated environmental sources, like household drinking water, and secondary transmission from poor hygiene practices in both the home and health facility, where family members care for patients [8-10]. Access to a safe domestic water source [9] and handwashing with soap [11] have been shown to reduce enteric diseases. However, acceptable and effective interventions tailored to meet the needs of diarrhea patients and their household members, both at a health facility and when they return home, are limited. Health facilitybased WASH interventions have been developed in various settings, though few interventions have reported on formative research conducted for intervention development [12-15].

\section{The Cholera-Hospital-based-Intervention-for-7-Days (CHoBI7)}

The original Cholera-Hospital-based-Intervention-for-7Days (CHoBI7) intervention program was designed for cholera patients and their household members [16]. To target a period of high susceptibility to diarrheal disease $[3,17,18]$, the intervention was delivered by health promoters during the seven-day period after the patient was admitted to a health facility for treatment-the high-risk period for the transmission of cholera and other diarrheal diseases $[3,5,6]$. The patient's hospitalization serves as a disrupting event for the household, creating an opportunity to introduce new behaviors [19].
Household members are both counseled on how to prevent cholera as well as provided with enabling technologies and supplies in order to facilitate behavior change.

The original intervention included a pictorial module (flipbook), delivered at the patient's bedside, that depicted how cholera spreads and can be prevented. The CHoBI7 moniker is based on the flipbook, as chobi means 'picture' in Bangla. After the bedside visit, behavioral recommendations were reinforced via daily household visits during the week following admission to the health facility. Enrolled households received an imported, sealed drinking water vessel with tap (Topaz $^{\text {Tm }}$ [Lion Star Plastic, Jakarta, Indonesia]), chlorine tablets for water treatment, a handwashing station, and a bottle of soapy water (detergent powder mixed with water). Target behaviors included drinking water treatment with chlorine tablets and handwashing with soap at key times (e.g. after using the toilet) during the 7 days following admission to a health facility. Households were counseled to continue protective WASH behaviors after the high-risk period in order to prevent future enteric infections. The original design of the CHoBI7 intervention program was informed by the Risk, Attitudes, Norms, Abilities, and Self-regulation (RANAS) model of behavior change [20] and the Integrated Behavioural Model for Water, Sanitation, and Hygiene (IBM-WASH) [21].

A randomized controlled trial (RCT) of the original CHoBI7 intervention program showed significantly fewer symptomatic cholera infections and a $47 \%$ reduction in overall cholera infections among those in the intervention arm versus the control arm [16]. Furthermore, intervention household members had significantly higher instances of handwashing with soap and significantly less E.coli in stored drinking water when compared to control households 6-12 months post-intervention delivery [22]. In our assessment of the underlying mechanism of behavior change, response efficacy was associated with habit 
formation, and disgust, convenience, and cholera awareness were associated with habit maintenance [23]; this points to the importance of considering behavior change theory in the development and implementation of WASH interventions. Interventions informed by behavior change theories that target multiple behavioral determinants are more likely to be successful than interventions that provide information alone [24-26].

\section{Setting and study rationale}

At the request of our partners at the Bangladesh Ministry of Health and Family Welfare, we aimed to develop a scalable approach to integrate the $\mathrm{CHoBI} 7$ intervention program into services provided at government and private health facilities in Bangladesh. We also aimed to tailor the intervention program for the household members of all diarrhea patients, irrespective of the etiology of disease. To achieve these aims, formative research and the engagement of key stakeholders were required in order to modify the original intervention program. The formative research addressed four research questions: (1) What are existing WASH and diarrhea patient care practices in health facilities? (2) What are households' experiences with and acceptability of CHoBI7 WASH enabling technology and behavioral recommendations? (3) What are considerations and modifications for taking the intervention program to scale? (4) What modifications to the original $\mathrm{CHoBI} 7$ intervention program are needed in order to tailor the intervention for the target population?

The goal of the present research was to develop the content and delivery method of a 'modified' CHoBI7 intervention program that would require only a single in-person visit in the health facility and could be integrated into services provided to diarrhea patients in health facilities in Bangladesh. Given the objective of developing an intervention program that could be taken to scale, a mobile health (mHealth) program was developed to accompany the health facility-initiated program. Formative research for the development of the CHoBI7 mHealth program is reported elsewhere [27]. The modified intervention was recently evaluated through a three-arm RCT, which took place over 12 months, that compared (1) the standard recommendation to diarrhea patients about oral rehydration solution (ORS) use; (2) health facility initiation of CHoBI7 plus mHealth (mHealth with no home visits); and (3) health facility initiation of CHoBI7 plus two home visits and mHealth (mHealth with home visits) (Fig. 1) (George et al. 2020, submitted).

\begin{tabular}{|c|c|c|c|}
\hline & Standard Arm & $\begin{array}{l}\text { mHealth with no home } \\
\text { visits }\end{array}$ & $\begin{array}{l}\text { mHealth with two home } \\
\text { visits }\end{array}$ \\
\hline \multirow[t]{2}{*}{$\begin{array}{c}\text { Key } \\
\text { Activities }\end{array}$} & 1 health facility-based visit & $\begin{array}{c}1 \text { health facility-based visit } \\
+ \\
\text { mHealth program }\end{array}$ & $\begin{array}{c}1 \text { health facility-based visit } \\
+ \\
2 \text { home visits } \\
+ \\
\text { mHealth program }\end{array}$ \\
\hline & $\$$ & 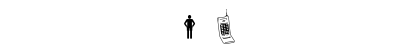 & 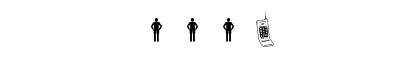 \\
\hline $\begin{array}{l}\text { Locations of } \\
\text { Interactions }\end{array}$ & Health facility & Health facility & Health facility and home \\
\hline $\begin{array}{l}\text { Intervention } \\
\text { Activities }\end{array}$ & $\begin{array}{l}\text { Deliver the standard } \\
\text { message on use of ORS } \\
\text { for dehydration }\end{array}$ & $\begin{array}{l}\text { Deliver the standard } \\
\text { message on use of ORS } \\
\text { for dehydration } \\
\text { - Provide CHoBI7 } \\
\text { enabling technologies to } \\
\text { households in the health } \\
\text { facility } \\
\text { - Deliver CHoBI7 Health } \\
\text { Facility Flipbook } \\
\text { module }\end{array}$ & $\begin{array}{l}\text { Deliver the standard } \\
\text { message on use of ORS } \\
\text { for dehydration } \\
\text { - Install CHoBI7 } \\
\text { enabling technologies in } \\
\text { households } \\
\text { - Deliver CHoBI7 health } \\
\text { facility flipbook module } \\
\text { - Deliver CHoBI7 } \\
\text { Household Flipbook } \\
\text { module }\end{array}$ \\
\hline
\end{tabular}




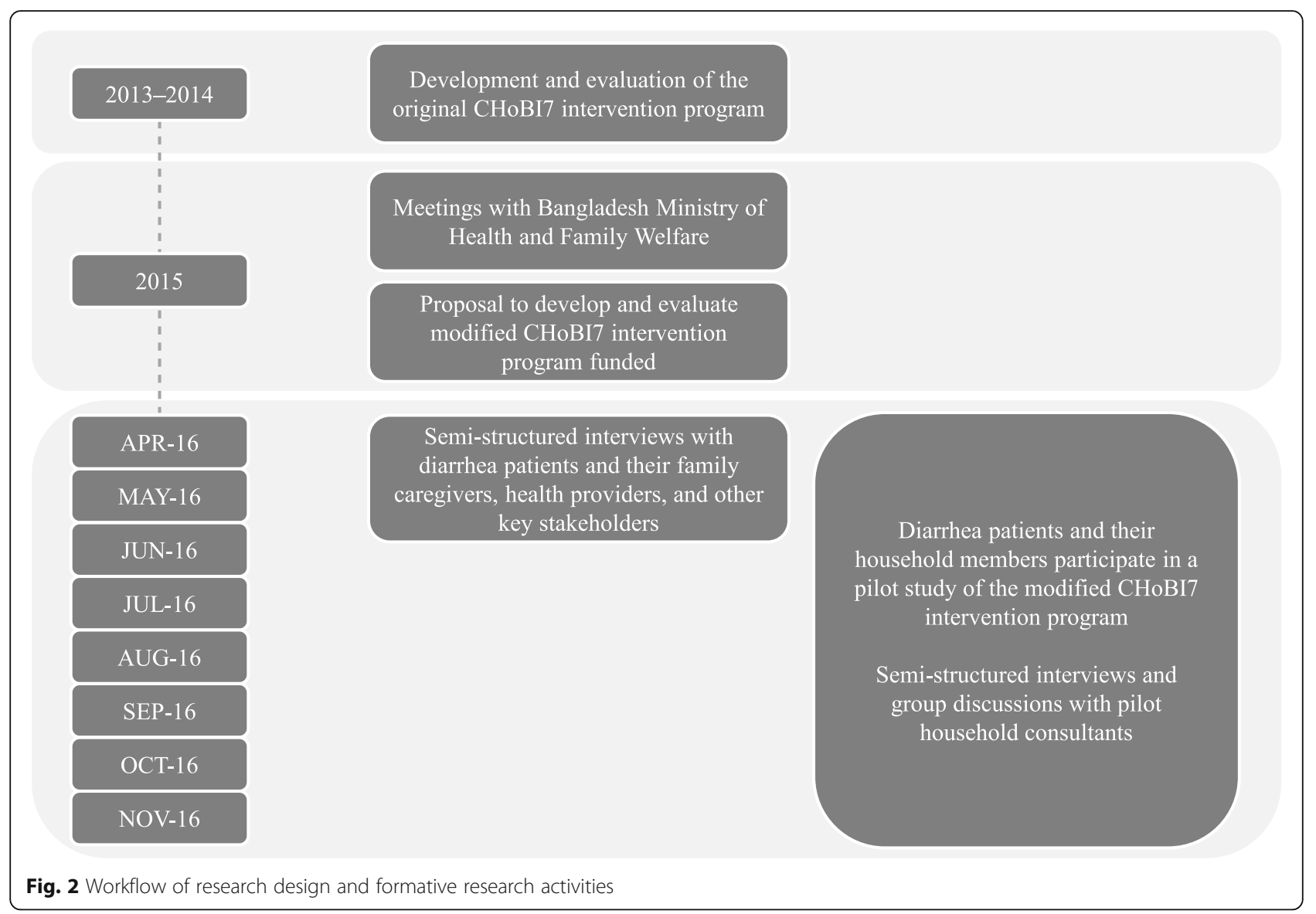

\section{Methods}

Semi-structured interviews and a pilot study for the development of the modified $\mathrm{CHoBI}$ intervention program were conducted in parallel. An outline of the formative research activities is provided in Fig. 2.

\section{Data collection}

A total of 60 semi-structured interviews were conducted from April to November 2016. Intial semi-structured interviews were conducted with a convenience sample of diarrhea patients $(n=5)$, their family caregivers $(n=13)$, and health providers $(n=2)$ to explore health facility WASH and patient care practices (Table 1). Diarrhea patients and their family caregivers were approached in the hospital, and the interviews took place at the patient's bedside. Interviews with health providers were arranged over the phone and conducted in the provider's office. The objective of these interviews was to identify practices and preferences that would necessitate modifications to the original $\mathrm{CHoBI}$ intervention program.

Twelve interviews with 10 key stakeholders (1 research scientist and 9 health-posting government officials) were also conducted to explore the scalability of the intervention (Table 1). One government stakeholder was interviewed 3 times. Government stakeholders were purposefully selected to include individuals serving in health services with decision-making power. Appointments for interviews with stakeholders were made over the phone or in-person, and the interviews took place in the interviewee's office.

From April through November 2016, trained research assistants recruited a convenience sample of 65 diarrhea patients and their household members to participate in a pilot study of the modified CHoBI7 intervention program for continued modification and refinement of the intervention content and delivery. For the pilot study, participants were recruited from 2 participating health facilities: icddr,b's hospital (private) and a government hospital in Dhaka, Bangladesh. Households were selected for participation if they (1) had a household member admitted to either health facility with three or more loose stools over a 24-h period, (2) had no basin with running water, (3) had a child under 5 years of age living in the home, (4) had at least one active mobile phone (for mHealth message delivery), (5) planned to reside in Dhaka over the following year, and (6) were not involved in another water treatment program. Possession of at least one active 
Table 1 Formative research activities

\begin{tabular}{|c|c|c|c|c|c|c|c|}
\hline \multicolumn{8}{|c|}{ Diarrhea patient, family caregiver, and health provider interviews } \\
\hline \multirow[t]{2}{*}{$\begin{array}{l}\text { - Explore WASH and patient care practices in health } \\
\text { facilities to assist with adapting the intervention for } \\
\text { delivery in public health facilities }\end{array}$} & & $\begin{array}{l}\text { Diarrhea } \\
\text { Patient, } \\
\text { Government } \\
\text { Hospital }\end{array}$ & $\begin{array}{l}\text { Diarrhea } \\
\text { Patient, } \\
\text { Private } \\
\text { Hospital }\end{array}$ & $\begin{array}{l}\text { Family } \\
\text { Caregiver, } \\
\text { Government } \\
\text { Hospital }\end{array}$ & $\begin{array}{l}\text { Family } \\
\text { Caregiver, } \\
\text { Private } \\
\text { Hospital }\end{array}$ & $\begin{array}{l}\text { Health } \\
\text { Provider, } \\
\text { Government } \\
\text { Hospital }\end{array}$ & Total \\
\hline & $\begin{array}{l}\text { Semi- } \\
\text { structured } \\
\text { interviews }\end{array}$ & 4 & 1 & 6 & 7 & 2 & 20 \\
\hline \multicolumn{8}{|l|}{ Key stakeholder interviews } \\
\hline \multirow[t]{2}{*}{$\begin{array}{l}\text { - Address research questions related to scalability of } \\
\text { the intervention }\end{array}$} & & \multicolumn{2}{|c|}{$\begin{array}{l}\text { Health-Posting Government } \\
\text { Official }\end{array}$} & \multicolumn{3}{|l|}{ Senior Scientist } & Total \\
\hline & $\begin{array}{l}\text { Semi- } \\
\text { structured } \\
\text { interviews }\end{array}$ & \multicolumn{2}{|l|}{11} & \multicolumn{3}{|l|}{1} & 12 \\
\hline \multicolumn{8}{|c|}{ Pilot household consultant interviews and group discussions } \\
\hline \multirow{3}{*}{$\begin{array}{l}\text { - Learn about households' experiences with the } \\
\text { intervention and promoted behaviors, and seek } \\
\text { advice for how to improve the intervention for the } \\
\text { upcoming trial }\end{array}$} & & \multicolumn{2}{|c|}{ Standard Message } & \multicolumn{2}{|c|}{ mHealth with no home visits } & $\begin{array}{l}\text { mHealth with } \\
2 \text { home visits }\end{array}$ & Total \\
\hline & $\begin{array}{l}\text { Semi- } \\
\text { structured } \\
\text { interviews }\end{array}$ & \multicolumn{2}{|l|}{-} & \multicolumn{2}{|l|}{17} & 11 & 28 \\
\hline & $\begin{array}{l}\text { Group } \\
\text { discussions }\end{array}$ & \multicolumn{2}{|l|}{-} & \multicolumn{2}{|l|}{-} & $\begin{array}{l}2 \text { (19 } \\
\text { Participants) }\end{array}$ & 2 \\
\hline
\end{tabular}

mobile phone was required for participation in the pilot study due to the pre-determined inclusion of mHealth as part of the intervention in order to facilitate future scaling up of the intervention program.

Household members of diarrhea patients were eligible for enrollment if their meals were prepared in the same cooking pot as the diarrhea patient for the 3 days prior to the diarrhea patient's admission to a health facility and if they planned to reside with the diarrhea patient for the next 12 months.

Two households refused to participate after initiating the hospital-based structured observation (activity distinct from the formative research presented here). Eleven households were dropped post-consent either because the study team could not locate the household or the patient left the hospital before receiving the intervention. A total of 52 households completed the pilot study, and 38 households were in the CHoBI7 mHealth arms.

The pilot study design included the three predetermined arms of the planned RCT (outlined above), with households assigned to either the (1) standard recommendation arm; (2) CHoBI7 mHealth with no home visits arm; or (3) CHoBI7 mHealth with two home visits arm. Intervention arms also received the standard ORS message. While the intervention arms of the pilot study helped to further tailor the intervention program, the standard recommendation arm served as a comparison group to inform operability and is separate from the formative research presented here.

The modified intervention program included a Health Facility Flipbook about how to prevent diarrhea transmission, which was delivered by a trained health promoter to all intervention households at the patient's bedside. Households in the mHealth with home visits arm received additional counseling from health promoters using a separate Household Flipbook during two household visits. All intervention households received a handwashing station (a red bucket with tap and lid, a bowl to catch rinse water, and a stool), a soapy water bottle $(500 \mathrm{~mL}$ bottle, with a pierced lid for dispensing liquid, with detergent powder dissolved in water inside), a safe water storage bucket (a blue bucket with tap and lid and a stool), and a 30-day supply of chlorine tablets for water treatment (Fig. 3). In the mHealth with no home visits arm, the hardware was provided in the hospital; the mHealth with home visits arm received hardware during the first home visit.

Of the 38 households enrolled in the pilot study CHoBI7 intervention arms, 27 households were visited for a follow-up interview (median 6.5 days between enrollment and follow-up) to learn about households' acceptability of and experiences with the intervention's enabling technologies and behavioral recommendations, and to seek advice for how to improve the intervention program. One household was visited twice, for a total of 28 pilot study interviews (Table 1). Pilot study participants were called consultants for the CHoBI7 intervention program and were told about their role in an effort to reduce courtesy bias. Follow-up interviews were conducted until we reached saturation. 


\begin{tabular}{|l|l|l|}
\hline $\begin{array}{l}\text { Handwashing } \\
\text { station }\end{array}$ & $\begin{array}{l}\text { A 16-liter, red, plastic bucket with a fixed } \\
\text { tap, lid, stool for bucket placement, and bowl } \\
\text { (basin) to collect used water. }\end{array}$ \\
\hline Soapy water bottle & $\begin{array}{l}\text { Any half-liter plastic bottle with a hole } \\
\text { drilled into the cap and filled with a mixture } \\
\text { of water and 6 capfuls of detergent powder. }\end{array}$ \\
\hline $\begin{array}{l}\text { Safe water storage } \\
\text { bucket }\end{array}$ & $\begin{array}{l}\text { A 12-liter, blue, plastic bucket with a fixed } \\
\text { tap, stool for bucket, and lid. }\end{array}$ \\
\hline Chlorine tablets & $\begin{array}{l}\text { 30 chlorine tablets to treat water stored in the } \\
\text { safe water storage bucket. }\end{array}$ \\
\hline
\end{tabular}

Fig. $3 \mathrm{CHoBl}$ enabling technology

Two group discussions $(n=7$ and $n=12)$ were conducted with a convenience sample of pilot study intervention household members to explore the same topics in a group setting and for additional intervention content development. Select findings from initial interviews or early visits to pilot study households were shared and discussed with group discussion participants to facilitate discussion and request feedback on intervention improvement.

Interviews with diarrhea patients and caregivers, health providers, and pilot study participants, as well as the group discussions, were conducted in Bangla by native speakers after extensive training. Ten of the 12 stakeholder interviews were conducted in English and two were conducted in Bangla. All interviews and group discussions were conducted by members of the CHoBI7 research team, who had at least master's level education in public health or social sciences, after training in qualitative data collection. Interviews and group discussions were done with pre-tested guides, to explore research questions; follow-up probes were used to further explore participants' responses. Fifty-nine of the 60 interviews and both group discussions were audio recorded. One government stakeholder declined to have their interview recorded. Interviews lasted between $12 \mathrm{~min}$ (family caregiver) and $190 \mathrm{~min}$ (stakeholder). The group discussions were 127 and $165 \mathrm{~min}$. Extensive field notes were taken by both the interviewer and any present observer to supplement recordings.

\section{Data analysis}

Analysis of the interviews and group discussions was completed in three phases (Fig. 4). In the first phase, interviews $(n=24 ; 13$ diarrhea patient/family caregivers and 11 pilot study) were followed by extensive debriefing to allow for iterative probing on emerging themes [28]. Second, a selection of interviews $(n=39 ; 16$ diarrhea patient/household member, 14 pilot study, 9 stakeholder) was transcribed verbatim in the language in which the interviews were conducted. Transcriptions were reviewed by at least one other member of the research team for quality control. Transcriptions were not returned to participants for their review. The transcriptions were then used to develop a summary template or 'analysis questionnaire,' based on components of the intervention and emergent themes. Finally, the analysis questionnaire was completed for all pilot study interviews. Group discussions were summarized, and selected quotes were transcribed. Field notes further supplemented transcriptions and summaries. Completed analysis questionnaires, transcriptions, and group discussion summaries were reviewed to identify and 


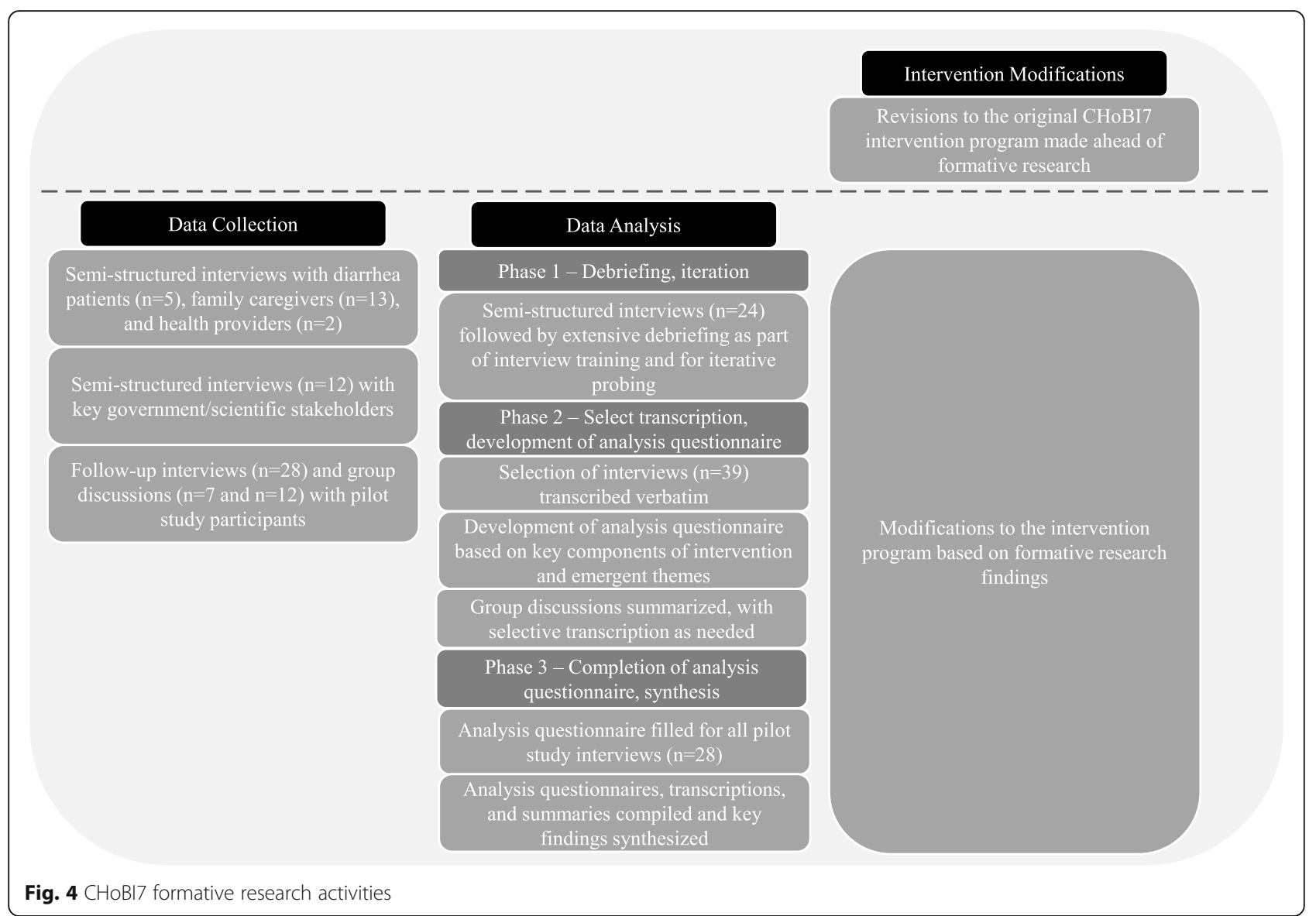

compile key findings and quotes for each intervention component. Based on formative research findings, modifications to the $\mathrm{CHoBI} 7$ intervention program were made throughout the data collection and analysis process.

\section{Data synthesis}

For the final synthesis of findings, contextual, psychosocial, and technological factors that emerged from formative research were organized using the IBM-WASH framework.

\section{Results}

Findings are presented by research question and include insights into WASH and diarrhea patient care practices in health facilities, pilot study feedback on enabling technologies and behavioral recommendations, and considerations for scalability that emerged from discussions with key stakeholders.

\section{What are existing WASH and diarrhea patient care practices in health facilities?}

Treated drinking water (filtration) was available for consumption at icddr,b but not at the government facility. However, in both health facilities, patients and their family members often brought their own drinking water, such as purchased bottled water or boiled water from home. One health provider at the government facility specified that family members were counseled to bring in boiled water for patients because the quality of water at the facility could not be guaranteed. At icddr,b, one caregiver cited crowding near the facility's water filter and the filter's slow flow rate as reasons why he purchased bottled water during his family's stay.

Soap was also brought by patients' families. Icddr,b provided liquid soap at sinks, though participants said not all sinks had soap. Some families brought in soap or detergent for personal use, such as to wash kanthas ('blankets') used by patients. Although handwashing facilities at icddr,b were considered satisfactory, caregivers still reported barriers to handwashing:

"... Here [icddr,b], the mother can only stay with the patient, so I will take care of the baby or myself. That's why [handwashing is] not done properly. But, in [the] home, if someone helps, then we can take care [of the child] properly. Now, here, do I have to take care of the baby or wash hands? ... If someone is with me, then I can keep my child neat and clean. Here it is not possible." 
At the government facility, handwashing and toilet facilities were considered poor by patients and providers. One patient reported visiting the toilet and not being able to wash his hands due to lack of soap. Project staff found that hardware on sinks adjacent to the diarrhea ward was broken or missing. One health provider noted that they did not have a sufficient soap supply to meet handwashing needs, and they had never visited the facilities for the patients.

Health facilities limit the number of caregivers that can attend a patient. Some mothers said that they could not leave to wash their hands or relieve themselves for fear that their child would roll off the bed in their absence. Another concern was that a child might defecate while the caregiver was being served food. Indeed, interviewers noted missed opportunities for handwashing during interviews, sometimes because the patient required care at that same moment.

Patients and their family caregivers were asked whether anyone from the health facility had provided health-related information. One participant at icddr,b said that a nurse had discussed saline intake and iron supplements. Another patient said that no one had been by because the staff were too busy and that he preferred to discuss health issues with family. Health providers at the government facility said that patients were given hygiene recommendations upon discharge, which may explain why, during our interviews (before discharge), very few participants were able to recall their receiving health advice from health facility staff.

What are households' experiences with and acceptability of $\mathrm{CHoBI7}$ WASH enabling technology and behavioral recommendations?

\section{Chlorine tablets for water treatment}

Pilot participants reported various household water treatment practices prior to enrollment into the pilot study, including consumption of kaccha pani ('raw, untreated water') from municipal water pumps or tube wells and filtering and/or boiling water. For most, use of chlorine for water treatment was a new practice, though some participants were familiar with a local water purification tablet called Halotab ${ }^{\circ}$. Most participants after receiving $\mathrm{CHoBI} 7$ intervention delivery in the health facility were able to describe the proper use of the intervention-provided Aquatabs ${ }^{\circ}$ (chlorine tablets) for water treatment. However, some participants struggled to recount the correct water-to-tablet ratio or the length of time water could remain safe for consumption after treatment. A few participants expressed concern for human error, such as taking the tablets as medicine, even though the flipbooks included a pictorial warning to not ingest the chlorine tablets directly. Still, the chlorine tablets were often referred to as aushoodh ('medicine'). One patient attributed his recovery to the chlorine tablets:

"I'm good now only [because of] this chlorine tablet. If I didn't get this tablet, I would not have been healthy."

Discussions about the chlorine tablets often turned to the taste and smell of chlorine-treated water. Participants said treated water smelled or tasted like "gas" or "medicine." Though most participants mentioned taste as a concern, many said they were able to overcome it within a few days:

"If they drink this water one or two days, they will get used to it ... Perhaps they would feel bad [for the] first one or two days, [but] they will be okay after that. I felt bad [for the] first few days, but now I got used to [it]."

One participant said she had served the chlorinetreated water to employees in her shop, and they liked it. However, some households said they stopped using chlorine-treated water shortly after returning home from the health facility, citing aversion to taste or smell, concern that the water was not safe for consumption, or an upset stomach as reasons for discontinuation.

For those who did regularly use the chlorine tablets, the convenience of the tablet compared to boiling drinking water was frequently mentioned:

"[The] tablet is a shortcut system and more convenient ... it takes only 30 minutes. Boiling needs more than 30 minutes ... Sometimes there is no gas supply for the stoves, or sometimes the supply water is too smelly and dirty to boil it. That's why I think tablets are better."

Challenges with boiling water, such as restricted stove access, gas supply, or time limitations, made chlorination an appealing alternative. That said, most participants said they would boil to treat water after the 30-day supply of chlorine tablets ran out. Several individuals said they looked for chlorine tablets in the market; others said it would be best if they were given more tablets. We recommended using chlorine-treated water to wash fruits and vegetables eaten raw, but one participant said this would be a waste of treated water.

\section{Safe water storage}

At the time of the interviews, most participants were using the intervention-provided blue bucket with tap for storage of either chlorine-treated or boiled water for drinking. Participants expressed appreciation for the functionality 
and convenience of the safe water storage bucket. For the most part, the bucket was considered good quality and durable. Several participants preferred a larger bucket (e.g. 20l) to accommodate drinking water needs, though one participant noted that people may not be able to lift buckets if they were larger, and another said that the 101 size was best to help with measuring water amounts to be treated with chlorine tablets.

Households reported using a traditional water storage vessel, or kolsi, either alongside or prior to the receipt of the safe water storage bucket. A preference for the plastic bucket over the metal kolsi was common; one reason was because plastic would not rust. Both the lid and tap were also important features of the bucket:

"A tap is attached to this [bucket]. If it were a normal bucket, [people] would say, 'Why will we use this bucket instead of a kolsi? [The] kolsi is perfect for me.' But, since this bucket has a tap, I can take water from this bucket through this tap. It is a shortcut with less trouble."

The lid was seen as a means to keep dirt and hands out of drinking water, something that kolsis did not always have. One concern about the tap was durability, as some taps initially leaked. One participant did not think she could replace the tap if she needed to buy a new bucket, saying she would need to return to dipping her hand in the bucket with a cup. Another said she would pay 200300 BDT (3.50 USD) for a new tap because she was accustomed to it now. The actual cost of the tap in the local market is 25-40 BDT (0.30-0.48 USD). One suggestion given by a participant was to fix the tap one inch higher to make it less likely to break. Another issue was that children would open the tap and spill/waste water; one participant stored her drinking water in plastic bottles as a result. On the other hand, the tap was also seen as a means for children to access safe drinking water:

"I like this bucket because it has a tap. My kids couldn't pour water from the storage [container] before, but now they don't have to pour it. They can just open the tap and drink from it using a mug."

Interestingly, three participants mentioned plastic quality, naming the company (a popular plastics company in Bangladesh) where project buckets were sourced by name and saying that this plastic "did not harbor germs" or "had no typical plastic smell." One maintenance issue mentioned was that the bucket would sometimes acquire a "slimy layer" when water was kept in it for too long, making regular cleaning and drying of the bucket necessary. Two participants mentioned leaving their buckets with relatives; one reason given was lack of space.

\section{Handwashing station and soapy water bottle}

Many discussions about the handwashing station (water storage bucket with tap, bowl to catch rinse water, stool to elevate bucket, and soapy water bottle) began with a recitation of the key times for handwashing promoted in the flipbooks. Several households reported that the frequency of handwashing in the family had increased since intervention delivery:

"We used to wash our hands after coming from the toilet and going out for a walk. After coming from the walk, we used to eat and feed our children without washing hands. But, now, after coming from outside, we wash our hands and then feed the children. The water and the soap are here."

As noted, one reason mentioned for the increase in handwashing was that "everything was in one place." The handwashing station served as a facilitator and a reminder to wash hands with soap. A key difference from typical practice was that handwashing inside or near the house was made possible by the handwashing station:
"There's a bucket, a bowl, and soap there [at the household entrance]. We wash our hands easily with soap there after coming from outside. But, if there is no such arrangement, we have to go to the tube well and press it for water. Moreover, there are women there. Men do not always want to go there in the middle of the women." (Female participant).

The need to visit a water pump to wash hands was viewed as an inconvenience and barrier to handwashing immediately following a contaminating event (e.g. using the toilet); pumps were reported to be crowded and required the use of communal bar soap, which several participants considered unhygienic:

"In the case of bar soap, many people use the same soap; germs and disease spread in this way. I think the soapy water is better."

One participant stated that the soapy water was the "most useful" CHoBI7 intervention component. Soapy water was considered easy to make, affordable, and to produce a better lather compared to bar soap. Participants said neighbors or relatives inquired about soapy water and later made it themselves. That said, one participant did not believe soapy water could remove germs, stating "After all, it is laundry detergent." Another participant said the soapy water caused a "burning sensation" on her hands.

When asked what challenges could come between handwashing with soap at key times, participants said that 
"laziness," "busyness," and the distraction of children were barriers. Participants also said project staff had motivated household members, and it was now up to individuals to adopt the recommended behaviors. Additional recommendations included promoting regular nail-cutting and having multiple handwashing stations (e.g. one for inside and one near the kitchen). Similar to the safe water storage bucket, young children would play with and spill the handwashing water and soapy water. One mother said she had to keep the bowl stored away when it was not in use because she was concerned that her child would play in the discarded handwashing water and become ill.

The stool was seen as a valuable part of the station:

"Since I have this stool, I can easily take water from [the handwashing station]. It would be difficult to take water if there was no stool-our hands might touch the ground while washing them. Germs could come to our hands from the ground."

Participants also stated that some of the handwashing stations were leaking. Other challenges included breaking the bowl and displacement of the tap. Two group discussion participants mentioned trying to fix the issues by themselves but needing to seek assistance.

The color distinction between the safe water storage bucket (blue) and handwashing station bucket (red) was considered helpful for separating "water for different uses," with someone mentioning that red indicated the bucket was not for drinking, like the red-marked tube wells that indicated arsenic:

"The color of the buckets is different, this is good. It helps to determine that this bucket is for drinking water and this one is for handwashing."

However, one group discussion participant said that people may be confused and think that the water in the red bucket contained arsenic.

Finally, one participant reported that her neighbors had started to use a bucket like hers to wash their hands "so they could live well and not need to go to the cholera hospital."

\section{Cue cards and flipbooks}

For the most part, participants felt the cue card design did not require modifications. Several commented on the importance of the pictures on the cards to help illiterate participants or children understand behavioral recommendations. One participant said the cue cards were superior to oral instruction. However, others said that people would not understand the cards without an accompanying explanation.

The cue cards were considered important reminders in case household members forgot the key times for handwashing with soap or how to use chlorine tablets. One participant referred to the cue cards as "friends" because they helped her stay healthy:

"These [cards] are like our friends; they are keeping us away from diseases, protecting us."

Hanging the cue cards in sight or adjacent to the related behavior (e.g. hanging the chlorine treatment cue card next to the safe water storage bucket) was recommended by participants. One participant recommended hanging cue cards outside so that others could see the cards and learn from them. A few participants reported not hanging the cards due to busyness or lack of space. One participant commented on the absence of repair/ maintenance information on enabling technologies in the flipbooks, pointing to a concern about guidance for how to resolve such issues.

\section{What are considerations and modifications for taking the intervention program to scale? \\ Enabling technologies and supplies}

Government stakeholders had experience with the aforementioned Halotab ${ }^{\circ}$ tablets, distributed in the past by the government during outbreaks or national emergencies (e.g. floods). Stakeholders were concerned about the population's acceptance of the tablet due to its taste and worried that the tablet might be misused as medicine. One government stakeholder suggested incorporating flavors, like strawberry, to the tablets to improve the taste. Important to note is that Halotab is no longer available on the local market. Some government stakeholders advised us to partner with local pharmaceutical companies for marketing chlorine tablets and to improve the taste of these tablets. A concern was that local pharmaceutical companies would not develop an alternative to Halotab $^{\circ}$ due to low anticipated demand and earnings. One stakeholder suggested a partnership with Non-Governmental Organizations (NGOs) to distribute Aquatabs to health facilities in the future, thereby avoiding the government-mandated tendering process.

In our discussions on hand hygiene, one stakeholder noted that the current government position on hygiene was that it was the responsibility of the individual:

"... Hygiene ... is now taken by [the] government as 'one individual, one hygiene.' Your hygiene, it will be by your own way ... Hygiene is now considered the individual level, not the state level ...".

The suggestion here was that hygiene interventions needed to be sustainable without long-term support 
of the government (e.g. continued provision of soap). Both liquid soap and hand sanitizer were said to be supplied in government health facilities, though for health professionals, only. To the stakeholders we interviewed, using detergent to wash hands was a novel concept that aligned with an ongoing government subsidy program by the Government to keep costs of detergent low:

"Detergent in Bangladesh is now very cheap. That is the government action. And people can buy [it] at low cost and can use [it]."

The same individual was surprised to learn that soapy water was made using the very same 'non-deluxe' (i.e. ordinary) detergent subsidized by the government. One stakeholder recommended we explore other detergents being used in the home to be sure they were suitable for soapy water and to keep in mind the growing use of liquid soap in households.

\section{Mass media for promoting $\mathrm{CHOBI} 7$ enabling technologies}

The majority of government stakeholders said it would be difficult to provide a handwashing station and drinking water container to all diarrhea patients in health facilities in Bangladesh. They recommended ensuring items were available in the market for people to buy and promoting them with a marketing campaign. Mass media was considered the best avenue to promote enabling technologies to households. One recommendation was to partner with major plastics companies in Bangladesh to market products using mass media and to make the handwashing station and drinking water vessel with tap as attractive as possible for marketing:

"They [the patients] have money to purchase this hardware, but this hardware should be available ... You motivate people to produce this type of hardware and they will popularize this hardware to the people through electronic media."

"The manufacturer should be responsible [for messaging] because [the hardware] is a commercial project ... we should talk with the manufacturer, convince them ... if you develop in this way, and sell it [for] 130 Taka, so you are getting a profit [of] 32 Taka. That will give the opportunity to the manufacturer to make ... more profit ... If you give the right messages in the advertisement-that is we'll ensure you the ... safe drinking water...people [will] buy it."

Television was the communication channel most recommended for delivering $\mathrm{CHoBI} 7$ behavioral recommendations. Radio, newspapers, and electronic media were also mentioned. It was recommended that we develop up to five short commercials, and to show these regularly through Bangladesh television channels. A scrolling message on the television was also suggested. The success of companies like Lifebouy (a 'health soap' marketed by Unilever) was mentioned as a potential model for CHoBI7, with one stakeholder calling Lifebuoy the "grand show for handwashing." Mass media campaigns were also encouraged for the marketing of chlorine tablets.

\section{Delivering the $\mathrm{CHOBI}$ intervention program in health facilities}

Stakeholders suggested that the scaling up of the CHoBI7 intervention program could involve health educators in government upazila ('sub-district') health complexes or community health providers at community clinics. Community clinics were said to have high coverage across the country; however, their health providers are known to have high workloads. One respondent recommended delivering the program at community clinics and hiring individuals to deliver the intervention. Health educators were considered to have the advantage of being located in upazila health complexes, where patients often stop first before going to community clinics.

A major challenge is the absence of community clinics and sufficient health educators in urban Bangladesh. For urban settings, it was recommended that we partner with local NGOs, urban health centers, government dispensaries, Dhaka Water Supply and Sewerage Authority, the Local Government Engineering Department, and Dhaka City Corporation to deliver the intervention program. Providing the handwashing station and safe water storage bucket directly to diarrhea patients was not considered a practical option for future scaling up of the intervention; one government stakeholder said that, if we gave diarrhea patients these items, the inventory would be exhausted within a month because individuals without diarrhea would come to facilities to collect them. One suggestion was for a demonstration handwashing station and drinking water container to be on display in health facilities for patients and family members to use as well as for health providers to recommend patients and their families buy these items after discharge:

"If you give ... these types of accessories [handwashing station and sealed water vessel] to the [health facility] ward ... and if it is available in the market, then they can tell the patients that, yes, now you're using it, go home and buy it and use it." 
There was general agreement that individuals would be willing to buy the enabling technologies. It was also noted that many households already had these items in their homes (e.g. bucket, stool, basin) but were not using them for WASH purposes.

Government stakeholders recommended that doctors, nurses, and health facility support staff be trained to deliver the CHoBI7 intervention program:

"It will be more effective if you train our health educator(s), because we have health educator(s) in every district and every upazila health complex ... Every day, they [will] give [the] message to the outpatient(s) or people coming in the hospitals ... First you have to train them ... as well as the doctors and the supporting staff also ... and you put this hardware set, one set, in every hospital."

The 'diarrhea corner' or 'ORT (Oral Rehydration Therapy) corner' present at many health facilities, where the use of ORS is promoted, was mentioned as an ideal location for delivering an intervention. It was recommended that the Health Facility Flipbook be delivered to both admitted and outpatient diarrhea cases and that posters or leaflets be given to patients.

Several government stakeholders mentioned that there would be room for the CHoBI7 intervention program in upcoming, already-funded initiatives. Others said that, for the intervention to be taken to scale, funding would need to be secured. Government stakeholders recommended $\mathrm{CHoBI} 7$ be part of the upcoming National Operational Plan for Communicable Diseases Control (CDC) Department:

"If you include this [the CHoBI7 program] in the CDC operational plan to train up the health educators ... the Health Education Bureau, they will include this soap [and] hand washing [recommendations] ... they [will] include these activities to train-up five hundred to one thousand people."

Integration of the $\mathrm{CHoBI} 7$ intervention program with existing government programs, such as a weekly health awareness program delivered at upazila health complexes, was mentioned as a method to minimize cost. It was also recommended that WASH behavioral recommendation development be done through the Health Education Bureau. One individual stated that, before the program could be recommended for scaled-up delivery, evidence that the intervention was effective would need to be published.
What modifications to the original $\mathrm{CHoBI} 7$ intervention program are needed to tailor the intervention for the target population?

In preparation for the formative research presented here, revisions to the original $\mathrm{CHoBI} 7$ intervention program, enabling technologies, and behavior change communication plan were made ahead of initiating the research activities presented here. These updates were based on experiential knowledge of the study setting, previous formative research, and pre-determined changes in program content (i.e. focus on all diarrhea etiologies). For example, the wording of the flipbooks was updated to focus on all types of diarrhea rather than just on cholera. Data collection to inform the development of the scalable approach to $\mathrm{CHoBI} 7$ was initiated after these preliminary updates.

The following additional modifications were made to the intervention program based on formative research findings both to tailor the intervention to target households as well as to address considerations for scalability (Table 2).

\section{Chlorine tablets for water treatment}

Given that the taste of water treated with chlorine was a concern expressed by most, a comparison of chlorine to local foods and plants that are health-protective but have a bitter taste (e.g. neem plant and bitter gourd) was added to the flipbooks [29]. In addition, during intervention delivery in health facilities, all family caregivers present were given a taste of chlorine-treated water and were probed to discuss their concerns, giving health promoters the opportunity to counsel them on the taste. Based on the finding that many patients and household members thought that chlorine tablets were curative, participants were reminded that the tablets were not medicine but were a method of water treatment. Household members were also counseled on how to make the transition from chlorine-treated water to boiled water after the 30-day supply of tablets was finished.

\section{Safe water storage}

The original CHoBI7 intervention program had included an imported safe water storage container. During piloting, project staff met with local plastic suppliers to select a durable plastic bucket option for the safe water storage bucket and handwashing station and their accompanying stools. Based on pilot household feedback, the initial taps for both buckets were switched out early on in the pilot for a sturdier option, and extra washers were added to limit the possibility of leaks. Given households' concern for build-up on the bucket related to long-term water storage, we also included a recommendation to clean the bucket once per week. Initially, we considered 
Table 2 Modifications to the original intervention package based on formative research findings, and considerations for scalability

\begin{abstract}
Original CHoBl7 Intervention Design
Health facility-initiated intervention

delivered by health promoters to

cholera patients and their household

contacts over the 7-day high-risk

period for transmission of disease to

household members.

Pictorial module on how cholera spreads and can be prevented, delivered by a health promoter at the patient's bedside.

Communication module reinforced during daily household visits during the one-week intervention period.
\end{abstract}

Imported, sealed drinking water vessel.

Chlorine tablets for water treatment

Handwashing station

Formative Research Finding Modified Intervention Design

Health facility-initiated intervention delivered by health promoters to diarrhea patients and their household contacts in the health facility over the 7-day high-risk period following admission to the health facility.

Pictorial module on how diarrhea spreads and can be prevented, delivered by a health promoter at the patient's bedside.

Mobile messages reinforced either through only voice and text messages weekly for 1 year (mobile health (mHealth) with no home visits), or mHealth and two home visits.

Importance of using locally available items to maximize sustainability and keep cost of intervention low. Need for a durable tap. Importance of elevating water storage container from the ground for hygiene purposes. Absence of reliable potable water in some health facilities.

Recommendation (or preference) to bring in own source of drinking water for health facility stay. Residue build-up in safe water storage bucket.

Dislike of bitter taste of chlorinated water. Barriers to regular boiling of water.

Absence of safe drinking water source in health facility, or practice of bringing in own drinking water.

Trouble distinguishing chlorine as 'water treatment agent' rather than 'medicine'.

Handwashing aid needed at bedside. Misuse of enabling technologies. Use of handwashing station by children.
Locally made plastic bucket with lid and added durable tap. Provision of a stool to elevate bucket. Provision of chlorine tablets and one bottle of chlorine treated water for health facility stay. Messaging around cleaning the safe water storage bucket regularly to avoid build-up related to long-term water storage.

Chlorine tablets for water treatment. Messaging relating the taste of chlorine to local medicinal plants and bitter foods with health benefits. Messaging around chlorine as water treatment, not curative medicine. Taste tests of chlorinated water while in the health facility. 30-day supply of chlorine tablets is exhausted.

Provision of bottle of soapy water bottle for duration of health facility stay.

Additional information in the communication module around importance of enabling technologies for a safe and healthy environment to avoid misuse.

Additional messaging around teaching children how to use enabling technologies. Messaging on boiling water after the
Considerations for Scalability

Replacement for study-supported health promoters (e.g. health educators or nurses).

Utility of mass media channels to alleviate burden of health communication at the health facility. Cost of program materials provided at scale.

Market availability of promoted enabling technologies and supplies (e.g. handwashing station, safe water storage bucket, and chlorine tablets) Integration of intervention program into existing government health programs.

Low-cost, durable, locally made option will need to be made available on the market.

Availability of potable water in health facilities.

Low-cost, locally made option will need to be available via Bangladeshbased pharmaceutical companies

Low-cost, durable, locally made option will need to be made available on the market. 
Table 2 Modifications to the original intervention package based on formative research findings, and considerations for scalability (Continued)

\begin{tabular}{llll}
\hline Original CHoBI7 Intervention Design & Formative Research Finding & Modified Intervention Design & Considerations for Scalability \\
\hline \multirow{3}{*}{ Bottle of soapy water } & & & \\
& Need for healthy lather & Increased the ratio from 4 capfuls per & Current Government detergent \\
& from soapy water without & $500 \mathrm{~mL}$ to 6 capfuls per $500 \mathrm{~mL}$. & subsidies likely to support soapy \\
& drying of hands. & Recommended households make & water as a low-cost alternative to bar \\
& Need for multiple soapy & multiple soapy water bottles for & or liquid soap. \\
& water bottles. & placement in home, latrine, and & \\
& kitchen areas. & & \\
& &
\end{tabular}

recommending that all patients keep their safe water storage bucket in the health facility, but we found that limited space and sometimes-soiled floors made use of the bucket in the health facility for drinking water a challenge, even with the intervention provided stool. Following the finding that family caregivers and patients often brought their own water to the health facility during their stay, we decided to leave a bottle of chlorinetreated water for them to use during the remainder of their stay.

\section{Handwashing station and soapy water bottle}

Interviewers' observations and interviews with patients, family caregivers, and health professionals necessitated handwashing technology at the patient's bedside. We tried multiple modifications to the intervention during the pilot study period to facilitate health facility-based handwashing with soap. Ultimately, we decided to recommend that all intervention patients and caregivers keep a soapy water bottle and a separate bottle of water for rinsing to facilitate handwashing while in the health facility. We recommended that caregivers wash their hands using the soapy water over the plastic basins that were often available for storage and/or trash. In the mHealth with no home visits arm, households were given the handwashing station in the health facility since no subsequent home visits were conducted to provide intervention materials. Promoters asked patients and caregivers to use their own detergent powder for preparing soapy water, as many had brought this with them to the health facility. If they did not have their own detergent powder, we provided it.

Once individuals returned home, we encouraged households to make multiple soapy water bottles to facilitate handwashing at key times at different locations (e.g. latrine and kitchen areas). We also encouraged household members that left the house during the day to take a soapy water bottle with them to facilitate handwashing while away from home. We modified the detergent-to-water ratio for soapy water, increasing the ratio from four to six capfuls of detergent powder per $500 \mathrm{~mL}$ of water to ensure that a healthy lather was produced during handwashing. Following feedback about children not using the handwashing station, we added images and recommendations about the importance of teaching children how to use the
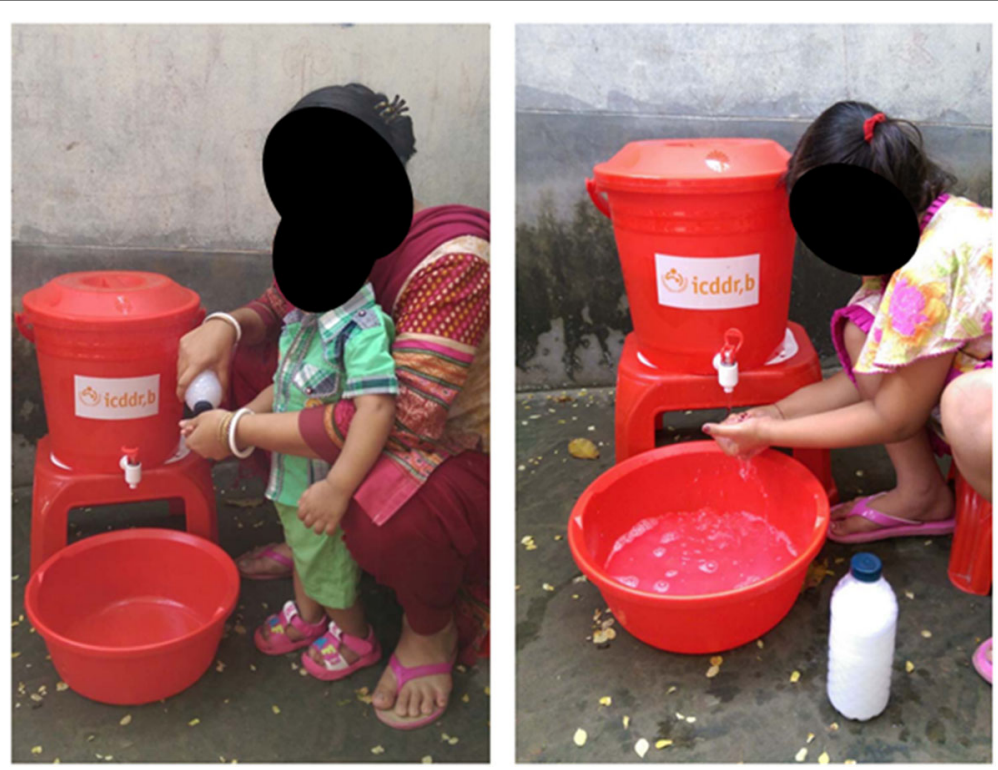

Fig. 5 Flipbook modification to include information on caregiver-assisted handwashing with soap for younger children 
Table 3 Key factors related to intervention components as organized by IBM-WASH

\begin{tabular}{|c|c|c|c|}
\hline & Contextual factors & Psychosocial factors & Technology factors \\
\hline Structural & $\begin{array}{l}\text { Government of Bangladesh mandated } \\
\text { tendering process for procurement of } \\
\text { goods (e.g. chlorine tablets, enabling } \\
\text { technologies, etc.). } \\
\text { Government of Bangladesh policy that } \\
\text { hygiene is the responsibility of the } \\
\text { individual. }\end{array}$ & $\begin{array}{l}\text { Government stakeholder interest in, and } \\
\text { prioritization of, a health facility-based } \\
\text { WASH intervention. }\end{array}$ & $\begin{array}{l}\text { Past use of chlorine tablets by Bangladesh } \\
\text { government during cholera outbreaks or } \\
\text { high-disease-risk events (e.g. floods). } \\
\text { Pharmaceutical company development and } \\
\text { provision of an affordable, locally-available } \\
\text { chlorine tablet. } \\
\text { Plastics company development and provision } \\
\text { of an affordable, locally-available } \\
\text { handwashing station and safe water storage } \\
\text { bucket. } \\
\text { Government subsidization of laundry } \\
\text { detergent. }\end{array}$ \\
\hline
\end{tabular}

\begin{abstract}
Health Access to/Condition of latrines, basin, Facility/ potable water, stove use/fuel in the Community compound or community. Access to/Condition of latrines, basin, potable water in public/private health facilities.

Access to markets and market goods (e.g. soap or detergent)

Public/private health facility resources and regulations.

Informal providers as initial point of treatment

Household Access to/Condition of, basin, potable water, stove use/fuel in the household. Responsibility for water collection, treatment, and storage.

Responsibility for children under five years of age.

Available space in home for

handwashing station and safe water

storage bucket.

Household size.
\end{abstract}

Individual Wealth, education, gender, livelihood of primary taker of children under five and primary decision-maker.

Age of children in household

Habitual

Environment allows for habit formation and limits habit disruptions.
Prevalence and expectation of promoted behaviors within the local and larger community.
Position of cue cards to increase visibility of key messages for neighbors of enrolled households.
Desire to develop and maintain a safe and hygienic household environment.
Modelling handwashing station use for children to reduce non-use or misuse..
Awareness of diarrheal disease transmission within the household/compound, and high perceived susceptibility of disease. High perceived benefits of adopting protective water, sanitation, and hygiene behaviors.

Disgust reaction in response to the information that diarrheal disease can be a result of consuming water or food contaminated with feces.

Response efficacy that practice of recommended WASH behaviors will reduce risk of diarrheal disease.

Existing water collection, treatment and storage practices. Existing hand hygiene practices.
Dislike of taste/smell of chlorine-treated water during. High perceived convenience of handwashing station, soapy water bottle, safe water storage bucket, and chlorine tablets compared to other options. Strengths/weaknesses of enabling technologies for users (e.g. size). and safe water storage bucket. Visible handwashing station, safe water storage bucket, and cue cards to serve as cues to action. handwashing station properly as they grew, emphasizing caregiver-assisted handwashing with soap for younger children and independent handwashing with soap for older children (Fig. 5).

Given the misuse of enabling technologies observed during the pilot study period, we emphasized the importance of using each item, as directed, for a safe and healthy home environment. Comical photos of technology misuse, including using the stool as a television stand and using the basin as a place for dirty dishes or clothing, were shown by the health promoter in the health facility, and misuse was discouraged.

\section{Flipbook and cue cards}

In the initial pilot rollout, there were six accompanying cue cards. Study staff deemed six too many 
because all available spaces on the walls in households were being covered with project materials. As a result, we reduced the number of cue cards from six to four. We also developed a sticker with a picture of a model family drinking water next to the safe water storage bucket and the accompanying message: "Germ free hands, safe water, make me healthy." We encouraged households to place the sticker on our intervention items, mirrors, or elsewhere in the home as a reminder to practice the behavioral recommendations.

\section{Synthesis of findings: IBM-WASH factors of influence for the $\mathrm{CHoBI}$ intervention program}

In Table 3, we organized the contextual, psychosocial, and technological factors identified from this formative research according to the IBM-WASH framework [21]. We were able to identify and modify multiple factors of influence through the formative research activities presented here, and organizing them with IBM-WASH helps to acknowledge the multiple levels and dimensions that influence WASH-related behaviors in this context. For example, interviews with diarrhea patients and their family caregivers, as well as with health care providers, provided important insights into the health facility environment (IBM-WASH community-level, contextual and technological dimensions), helping to highlight accessrelated barriers to the $\mathrm{CHoBI} 7$ behavioral recommendations that necessitated modifications to the intervention (e.g. provision of soapy water bottles in the hospital [Tables 2 and 3]). Pilot study participants' insistence that individuals would become accustomed to the taste of chlorinated water over time (IBM-WASH individuallevel, technological dimension) led us to front-load behavioral recommendations to help participants through their initial dislike of the taste of chlorinated water. We also realized that, as households finished their supply of chlorine tablets and needed to adopt boiling, we would need supportive mHealth messaging during the transition to alternative methods of water treatment that addressed identified constraints at the IBM-WASH household level. Finally, we identified several higherlevel contextual and technological factors that are typically out of the scope of WASH interventions but should be addressed or considered for scale-up, such as pharmaceutical company development and provision of an affordable, locally-available chlorine tablet.

\section{Discussion}

Formative research was critical for tailoring the CHoBI7 intervention program to our target population and for identifying approaches for scalable program delivery. Interviews with diarrhea patients and their family caregivers, government officials, and health providers, in addition to the pilot study of the intervention, informed our understanding of factors that are important for a household's adoption and maintenance of WASH behaviors, modifications needing to be made to intervention program materials, and considerations for delivering the CHoBI7 intervention program in public and private healthcare facilities in Bangladesh. With respect to existing WASH and diarrhea patient care practices in health facilities, interviews provided important insights into the health facility environment, including insights into gaps in diarrhea patient and family caregiver access to water and hygiene while in health facilities that could be filled by the CHoBI7 intervention program.

Pilot study feedback on intervention components was consistent with findings from other settings. For example, the role of taste with respect to acceptance of chlorine treated water has been well documented [18], and our modifications to the intervention to mitigate this concern could be applied in other contexts where treated water is part of an intervention. Similar to other research in Bangladesh, when interviewing pilot study participants, we found that having a handwashing station in the home facilitates handwashing by having all materials required for handwashing in one place; however, durability of the material, cost associated with alternative handwashing agents (e.g. low cost of laundry detergent), and disgust at sharing soap also play a role in whether or not the technology will be used [30]. Exploring households' experiences with and acceptability of $\mathrm{CHoBI} 7$ WASH enabling technology and behavioral recommendations allowed us to tailor the intervention to a specific population.

Interviews with government stakeholders provided valuable insights for scaling up of the $\mathrm{CHoBI} 7$ intervention program in Bangladesh. We learned that delivering $\mathrm{CHoBI} 7$ enabling technologies to all diarrhea patients in health facilities would likely not be feasible at scale. However, stakeholders recommended promising alternatives, including partnering with plastics and pharmaceutical companies to market enabling technologies and supplies through mass media. These partnerships should be pursued during the transition to scale. The successful scale-up campaign for zinc treatment of childhood diarrhea in Bangladesh that included private-sector participation presents a promising approach for scale-up of CHoBI7 intervention program components [31]. Another suggestion was to have a demonstration handwashing station and drinking water container on display in health facilities for patients and family members to use and for health providers to recommend their purchase. Outside icddr,b's hospital, shopkeepers sell items commonly used in the diarrhea ward (e.g. sippy cups and bedding). Partnerships with these individuals to sell 
CHoBI7 technologies could also be explored. In our recent RCT of the modified intervention (George et al., 2020 submitted), several neighbors of enrolled households made their own enabling technology using materials they obtained from the local market, which suggests that a model display in the hospital could facilitate uptake. Government stakeholder recommendations for integration of the $\mathrm{CHoBI} 7$ intervention program into the services provided in government upazila health complexes and community clinics are encouraging. Future research is needed to pilot the intervention program in these health facilities.

It is important to note that some recommendations made by government stakeholders were not possible to incorporate in this iteration of intervention adaptation (e.g. mass media campaign or selling of enabling technologies and supplies), given the intention to test the effectiveness of the intervention through an RCT. A key objective of this formative research was to define a more scalable approach for $\mathrm{CHoBI} 7$ program delivery. Developing a scalable intervention is an iterative process. The first iteration of the $\mathrm{CHoBI} 7$ intervention program was not scalable due to its intensive home visits. In the second iteration, presented here, we reduced the cost of enabling technologies, reduced the number of home visits in one arm, and eliminated home visits altogether in the mHealth with no home visits arm. We also added a mobile message component to reinforce the key behaviors promoted by the program over time. Our next step is to scale this program in partnership with the Ministry of Health and Family Welfare, incorporating the suggestions made by governmental stakeholders.

Mangham and Hanson identify four major challenges to scaling up interventions in international health: costs associated with scaling up coverage, scaling constraints, concerns for equity and quality, and issues related to service delivery [32]. Challenges with the reach, sustainability, and scalability of the CHoBI7 intervention program remain. First, a challenge to delivering the $\mathrm{CHoBI} 7$ intervention program in government health facilities is variability in the availability of WASH infrastructure, such as running water. Second, human resources in government health facilities in Bangladesh are often limited [33]. Third, in Bangladesh, informal health providers, including village doctors and pharmacists, may be visited before care is sought at a health facility [34, 35]. Future studies should assess approaches to include informal health providers.

The formative research presented here includes several strengths. One strength of the design was the involvement of pilot study participants as consultants to improve the intervention. This practice follows similar research [36] that suggests that the direct involvement of beneficiaries and an iterative process for intervention design comprise a valuable approach to tailoring interventions. A second strength was the iterative nature of the formative research, which allowed us to tailor the intervention as we learned and to explore emergent themes that further deepened our understanding of households' experiences with the intervention and behavioral recommendations. Finally, our partnership with key government stakeholders allowed us to consider pathways to scale early in the process and develop support for a scalable approach to the intervention.

Diarrhea remains a top reason for seeking care at a health facility in Bangladesh [37]. There is a high risk of transmission of enteric disease within the health facility and home for household members of diarrhea patients $[3-5,7]$. The CHoBI7 intervention program presents an important opportunity to intervene during this high-risk period, when perceived susceptibility of illness is high, perceived benefits of protective WASH behaviors are also likely to be high [18], and the environment is favorable for habit formation [19]. Other studies have also provided evidence that WASH interventions in health facilities can facilitate sustained behavior change [12, 15]. The CHoBI7 intervention program differs from more traditional, community-based WASH interventions, given that it is health facility-initiated and facilitates changes in behavior both in the health facility and once the patient and caregivers return home. Future work should prioritize WASH interventions for those at high risk of enteric diseases that can be taken to scale in health facilities-and sustained in households-to reduce future enteric disease episodes.

One limitation is that our interviews with pilot study participants were mostly with women. Although much of this imbalance was due to the availability of participants, the interviews we were able to conduct with pilot household men helped us to better understand how to incorporate their needs and schedules into our behavioral recommendations. Additional interviews with men may provide important insight into how to better balance household responsibilities related to WASH behaviors. Finally, future formative research should include interviews with health facility staff at multiple levels of care and management (e.g. doctors, nurses, and janitorial staff) to better inform our understanding of the practices and resources in health facilities that may impact delivery of the CHoBI7 intervention program.

\section{Conclusion}

Formative research identified existing WASH and diarrhea patient care practices, target population experiences with and acceptability of a health facility-initiated WASH intervention, and facilitated modifications to the CHoBI7 intervention program in an effort to identify a scalable approach to deliver this program in Bangladesh. 


\section{Abbreviations}

CHoBl7: Cholera-Hospital-based-Intervention-for-7-Days; WASH: Water, sanitation, and hygiene; IBM-WASH: Integrated Behavioural Model for Water, Sanitation, and Hygiene; RCT: Randomized controlled trial; ORS: Oral rehydration solution; icddr,b: International Centre for Diarrhoeal Disease Research, Bangladesh; NGOs: Non-Governmental Organizations; CDC: Communicable Diseases Control

\section{Acknowledgements}

The authors would like to thank all CHoBl7 study participants, the participating health facilities, supporting members of the Ministry of Health \& Family Welfare of Bangladesh, and other local partners that have made this work possible. The authors would also like to thank the larger $\mathrm{CHoBI7}$ study team for their support. ICDDR, B thanks the Governments of Bangladesh, Canada, Sweden, and the United Kingdom for core/unrestricted support.

\section{Authors' contributions}

EDT supported data collection, conducted data analysis and interpretation, and wrote the original draft of this manuscript. CMG conceived of the study design and directed the study. CMG and EDT designed the interview and focus group discussion guides. Interviews were conducted by MTH, TP, MKH, MH, FZ, and CMG. Group discussions were led by MTH and FZ. Data summaries and transcriptions were completed by MSR, MTH, TP, FZ, AT, MKH, MH, and EDT. FZ, AT, and JM supported intervention development and delivery. EDT, MSR, and PJW developed the data analysis questionnaire. MSR conducted data analysis and interpretation. MSIB contributed to data collection and led data management. ST, FM, MAHK, CMG, EL, and PJW critically reviewed and revised the original manuscript. DS, MA, and MS contributed to the design of the CHoBI7 study. CMG, MA, and SM directed data collection for the study. Al authors provided support and suggestions during the intervention development process and/or subsequent writing and review of this manuscript. All authors read and approved the final manuscript.

\section{Funding}

This study received financial support from the United States Agency for International Development (USAID-OAA-F-15-00038). The funder did not have a role in the design, implementation, or evaluation of the study.

\section{Availability of data and materials}

The datasets generated and/or analyzed during the current study are not publicly available due to identifiable content.

\section{Ethics approval and consent to participate}

Study procedures were explained to all participants by trained research assistants who collected written informed consent and/or parental permission from all participants ahead of study enrollment for the pilot study or standalone semi-structured interviews and group discussions. Participants were informed of the study objectives as part of the consent process. Prior to beginning interviews and group discussions, interviewers/moderators introduced themselves and their current position in the study team. The study was reviewed and approved by the Johns Hopkins Bloomberg School of Public Health Institutional Review Board and the Ethical Review Committee of icddr,b.

\section{Consent for publication}

Not applicable.

\section{Competing interests}

Christine Marie George is an Editorial Board Member of BMC Public Health. The other authors declare no competing interests.

\section{Author details}

${ }^{1}$ Department of International Health, Johns Hopkins Bloomberg School of Public Health, Baltimore, MD, USA. ${ }^{2}$ Infectious Diseases Division, International Centre for Diarrhoeal Disease Research, Bangladesh, Dhaka, Bangladesh. 3Johns Hopkins Bloomberg School of Public Health, Baltimore, MD, USA. ${ }^{4}$ Department of Communicable Diseases, Ministry of Health and Family Welfare, Dhaka, Bangladesh. ${ }^{5}$ Community Based Health Care, Directorate General of Health Services, Dhaka, Bangladesh. ${ }^{6}$ Associate Professor, Department of International Health, Program in Global Disease Epidemiology and Control, Johns Hopkins Bloomberg School of Public Health, 615 N. Wolfe Street, Room E5535, Baltimore, MD 21205-2103, USA.
Received: 8 December 2019 Accepted: 17 April 2020

Published online: 01 June 2020

\section{References}

1. Naghavi M, Abajobir AA, Abbafati C, Abbas KM, Abd-Allah F, Abera SF, et al. Global, regional, and national age-sex specific mortality for 264 causes of death, 1980-2016: a systematic analysis for the global burden of disease study 2016. Lancet. 2017;390(10100):1151-210.

2. Liu L, Oza S, Hogan D, Chu Y, Perin J, Zhu J, et al. Global, regional, and national causes of under-5 mortality in 2000-15: an updated systematic analysis with implications for the sustainable development goals. Lancet. 2016;388(10063):3027-35.

3. Weil AA, Khan Al, Chowdhury F, Larocque RC, Faruque AS, Ryan ET, et al. Clinical outcomes in household contacts of patients with cholera in Bangladesh. Clin Infect Dis. 2009:49(10):1473-9.

4. Echeverria P, Seriwatana J, Taylor DN, Yanggratoke S, Tirapat C. A comparative study of enterotoxigenic Escherichia coli, Shigella, Aeromonas, and Vibrio as etiologies of diarrhea in northeastern Thailand. Am J Trop Med Hyg. 1985;34(3):547-54.

5. George CM, Ahmed S, Talukder KA, Azmi IJ, Perin J, Sack RB, et al. Shigella infections in household contacts of pediatric shigellosis patients in rural Bangladesh. Emerg Infect Dis. 2015;21(11):2006-13.

6. Black RE, Merson MH, Rowe B, Taylor PR, Abdul Alim AR, Gross RJ, et al. Enterotoxigenic Escherichia coli diarrhoea: acquired immunity and transmission in an endemic area. Bull World Health Organ. 1981;59(2):263-8.

7. George CM, Hasan K, Monira S, Rahman Z, Saif-Ur-Rahman KM, Rashid MU, et al. A prospective cohort study comparing household contact and water Vibrio cholerae isolates in households of cholera patients in rural Bangladesh. PLoS Negl Trop Dis. 2018;12(7):e0006641.

8. Islam MS, Luby SP, Sultana R, Rimi NA, Zaman RU, Uddin M, et al. Family caregivers in public tertiary care hospitals in Bangladesh: risks and opportunities for infection control. Am J Infect Control. 2014;42(3):305-10.

9. Clasen T. Household water treatment and safe storage to prevent diarrheal disease in developing countries. Curr Environ Health Rep. 2015;2(1):69-74.

10. Zohura F, Bhuyian SI, Monira S, Begum F, Biswas SK, Parvin T, et al. Observed handwashing with soap practices among cholera patients and accompanying household members in a hospital setting (CHoBl7 trial). Am J Trop Med Hyg. 2016;95(6):1314-8.

11. Curtis V, Cairncross S. Effect of washing hands with soap on diarrhoea risk in the community: a systematic review. Lancet Infect Dis. 2003;3(5):275-81.

12. Sreenivasan N, Gotestrand S, Ombeki S, Oluoch G, Fischer T, Quick R. Evaluation of the impact of a simple hand-washing and water-treatment intervention in rural health facilities on hygiene knowledge and reported behaviours of health workers and their clients, Nyanza Province, Kenya, 2008. Epidemiology \& Infection. 2015;143(4):873-80.

13. Wood S, Foster J, Kols A. Understanding why women adopt and sustain home water treatment: insights from the Malawi antenatal care program. Soc Sci Med. 2012;75(4):634-42

14. Sheth AN, Russo ET, Menon M, Wannemuehler K, Weinger M, Kudzala AC, et al. Impact of the integration of water treatment and handwashing incentives with antenatal services on hygiene practices of pregnant women in Malawi. Am J Trop Med Hyg. 2010;83(6):1315-21.

15. Parker AA, Stephenson R, Riley PL, Ombeki S, Komolleh C, Sibley L, et al. Sustained high levels of stored drinking water treatment and retention of hand-washing knowledge in rural Kenyan households following a clinicbased intervention. Epidemiol Infect. 2006;134(5):1029-36.

16. George CM, Monira S, Sack DA, Rashid M-u, Saif-Ur-Rahman K, Mahmud T, et al. Randomized controlled trial of hospital-based hygiene and water treatment intervention (CHoBI7) to reduce cholera. Emerg Infect Dis. 2016; 22(2):233.

17. Rosenstock IM. Historical origins of the health belief model. Health Educ Monogr. 1974;2(4):328-35.

18. Figueroa ME, Kincaid DL. Social, cultural and behavioral correlates of household water treatment and storage. Center Publication HCl 2010-1: Health Communication Insights; 2010.

19. Neal D, Vujcic J, Hernandez O, Wood W. The science of habit: creating disruptive and sticky behavior change in handwashing behavior. Washington DC: USAID/WASHplus Project; 2015.

20. Mosler HJ. A systematic approach to behavior change interventions for the water and sanitation sector in developing countries: a conceptual model, a review, and a guideline. Int J Environ Health Res. 2012;22(5):431-49. 
21. Dreibelbis R, Winch PJ, Leontsini E, Hulland KR, Ram PK, Unicomb L, et al. The integrated Behavioural model for water, sanitation, and hygiene: a systematic review of behavioural models and a framework for designing and evaluating behaviour change interventions in infrastructure-restricted settings. BMC Public Health. 2013;13(1):1015.

22. George CM, Jung DS, Saif-Ur-Rahman KM, Monira S, Sack DA, Mahamud-ur $R$, et al. Sustained uptake of a hospital-based handwashing with soap and water treatment intervention (cholera-hospital-based intervention for 7 days [CHoBl7]): a randomized controlled trial. Am J Trop Med Hyg. 2016;94(2): 428-36.

23. George CM, Biswas S, Jung D, Perin J, Parvin T, Monira S, et al. Psychosocial factors mediating the effect of the $\mathrm{CHOBI7}$ intervention on handwashing with soap: a randomized controlled trial. Health Educ Behav. 2017;44(4):61325.

24. Briscoe $\mathrm{C}$, Aboud F. Behaviour change communication targeting four health behaviours in developing countries: a review of change techniques. Soc Sci Med. 2012;75(4):612-21.

25. Curtis V, Schmidt W, Luby S, Florez R, Touré O, Biran A. Hygiene: new hopes, new horizons. Lancet Infect Dis. 2011;11(4):312-21.

26. Inauen J, Mosler HJ. Developing and testing theory-based and evidencebased interventions to promote switching to arsenic-safe wells in Bangladesh. J Health Psychol. 2014;19(12):1483-98.

27. George CM, Zohura F, Teman A, Thomas E, Hasan T, Rana S, et al. Formative research for the design of a scalable mobile health program water, sanitation, and hygiene: CHoBI7 mobile health program. BMC Public Health. 2019;19(1):1028.

28. McMahon SA, Winch PJ. Systematic debriefing after qualitative encounters: an essential analysis step in applied qualitative research. BMJ Glob Health. 2018;3(5):e000837.

29. Qadri F, Ali M, Chowdhury F, Khan Al, Saha A, Khan IA, et al. Feasibility and effectiveness of oral cholera vaccine in an urban endemic setting in Bangladesh: a cluster randomised open-label trial. Lancet. 2015;386(10001):1362-71.

30. Hulland KR, Leontsini E, Dreibelbis R, Unicomb L, Afroz A, Dutta NC, et al. Designing a handwashing station for infrastructure-restricted communities in Bangladesh using the integrated behavioural model for water, sanitation and hygiene interventions (IBM-WASH). BMC Public Health. 2013;13(1):877.

31. Larson CP, Koehlmoos TP, Sack DA. Scaling up of zinc for young children project T. scaling up zinc treatment of childhood diarrhoea in Bangladesh: theoretical and practical considerations guiding the SUZY project. Health Policy Plan. 2012;27(2):102-14.

32. Mangham $L$, Hanson K. Scaling up in international health: what are the key issues? Health Policy Plan. 2010;25(2):85-96.

33. Ahmed SM, Hossain MA, Rajachowdhury AM, Bhuiya AU. The health workforce crisis in Bangladesh: shortage, inappropriate skill-mix and inequitable distribution. Hum Resour Health. 2011;9(1):3.

34. Das SK, Nasrin D, Ahmed S, Wu Y, Ferdous F, Farzana FD, et al. Health careseeking behavior for childhood diarrhea in Mirzapur, rural Bangladesh. Am J Trop Med Hyg. 2013;89(1 Suppl):62-8.

35. Ahmed SM. Exploring health-seeking behaviour of disadvantaged populations in rural Bangladesh: Institutionen för folkhälsovetenskap/ Department of Public Health Sciences; 2005

36. Harvey SA, Paredes Olortegui M, Leontsini E, Ramal Asayag C, Scott K, Winch PJ. Trials of improved practices (TIPS): a strategy for making longlasting nets last longer? Am J Trop Med Hyg. 2013;88(6):1109-15.

37. Sultana M, Mahumud RA, Sarker A. Emerging patterns of mortality and morbidity in district level hospitals in Bangladesh. Ann Public Heal Res. 2015;2:2-4.

\section{Publisher's Note}

Springer Nature remains neutral with regard to jurisdictional claims in published maps and institutional affiliations.

Ready to submit your research? Choose BMC and benefit from:

- fast, convenient online submission

- thorough peer review by experienced researchers in your field

- rapid publication on acceptance

- support for research data, including large and complex data types

- gold Open Access which fosters wider collaboration and increased citations

- maximum visibility for your research: over $100 \mathrm{M}$ website views per year

At BMC, research is always in progress.

Learn more biomedcentral.com/submissions 